\title{
Influence of cryoprotective diluent on post-thaw viability and acrosomal integrity of spermatozoa of the African elephant (Loxodonta africana)
}

\author{
J. G. Howard, M. Bush, V. de Vos*, M. C. Schiewe, V. G. Pursel† and \\ D. E. Wildt
}

National Zoological Park, Smithsonian Institution, Washington, DC 20008, U.S.A.; ${ }^{*}$ Kruger National Park, Republic of South Africa; and $\dagger U . S$. Department of Agriculture, Agricultural Research Service, Beltsville, MD 20705, U.S.A.

\begin{abstract}
Summary. Electroejaculates from free-ranging, African elephants were frozen to test various seminal diluents, freezing methods and thawing media on post-thaw sperm viability and structural integrity. In Study I, each ejaculate was tested with each of 7 cryoprotective diluents. After cooling to $5^{\circ} \mathrm{C}$ and equilibration on ice $\left(4^{\circ} \mathrm{C}\right)$ for $120 \mathrm{~min}$, each aliquant was pellet frozen on solid $\mathrm{CO}_{2}$, stored in liquid nitrogen and thawed $\left(37^{\circ} \mathrm{C}\right)$ in saline or tissue culture solution. Amongst all diluents, post-thaw sperm motility, motility duration in vitro $\left(37^{\circ} \mathrm{C}\right)$ and acrosomal integrity were greatest $(P<0.05)$ when diluent BF5F was used. Thawing medium had no effect on results. In Study II, the optimal diluent from Study I (BF5F) was compared with the diluent SGI. Results were not affected by a 90 - or a 150 -min cooling-equilibration interval in an electronic cooler $\left(5^{\circ} \mathrm{C}\right)$; however, post-thaw sperm motility rating and duration of motility in vitro were greater $(P<0.01)$ with the pellet than the straw container freezing method. When the pelleting method was used, diluents BF5F and SGI provided comparable cryoprotection. Duration of post-thaw motility was enhanced 2-fold and up to $12 \mathrm{~h}$ by maintaining thawed semen at 21 rather than $37^{\circ} \mathrm{C}(P<0.05)$. All diluents provided some protection on acrosomal integrity, but the overall proportion of intact acrosomes after thawing was markedly less in Study II, apparently as a result of the slower initial cooling rate $\left(\sim 1.5^{\circ} \mathrm{C} / \mathrm{min}\right)$ compared to that of Study I $\left(\sim 6.5^{\circ} \mathrm{C} / \mathrm{min}\right)$. This study demonstrates the feasibility of cryopreserving semen from free-ranging African elephants and indicates that spermatozoa must effectively survive freezing when the BF5F or SGI diluent is used in conjunction with the pelleting method.
\end{abstract}

\section{Introduction}

The artificial propagation of elephants has application in zoological collections because bulls are difficult to manage in captivity. The cryopreservation of spermatozoa for subsequent artificial insemination would allow breeding of isolated females without the hazards of maintaining unpredictable, frequently aggressive males. Furthermore, the international exchange of frozen semen would permit introducing new genetic material from wild, free-ranging herds to captive populations.

There are few reports on cryopreservation of elephant spermatozoa, partly because of animal unavailability and a lack of satisfactory semen collection procedures. African elephant spermatozoa (collected post mortem after flushing the excurrent testicular duct system) demonstrate a $44 \%$ post-thaw motility rating after being frozen in an egg-yolk-citrate diluent (Jones, 1973; Jones, Bailey \& Skinner, 1975). Cryopreservation of elephant spermatozoa collected in an artificial vagina from a domesticated Asiatic bull elephant (Heath, Jeyendran \& Graham, 1983) and by 
electro-ejaculation from a single African bull (Ruedi \& Kupfer, 1981) has been reported; however, poor post-thaw sperm recovery $(<5 \% ; 15 \%$, respectively) was observed. No other information is available.

Howard, Bush, de Vos \& Wildt (1984) have described an effective electroejaculation technique for recovering high quality ejaculates from wild, free-ranging African elephants. Using these procedures, the present studies were designed to: (1) examine the feasibility of freezing elephant spermatozoa under field conditions; (2) assess the cryoprotective abilities of various semen diluents on post-thaw viability including acrosomal integrity; (3) compare freezing methods, thawing media and maintenance temperatures for sustaining spermatozoa motility in vitro.

\section{Materials and Methods}

Animals, anaesthesia, semen collection and evaluation. Adult bull elephants free ranging in the $20000 \mathrm{~km}^{2}$ Kruger National Park were studied in August-September 1982 (N =6, Study I) and August 1984 ( $\mathrm{N}=7$, Study II). Males were singletons or associated with 1-3 other bachelor males. For electroejaculation, elephants were immobilized on one occasion by an i.m. dart injection with $10 \mathrm{mg}$ etorphine hydrochloride (M99: Reckitt \& Coleman, Hull, U.K.; Study I) or 12 mg carfentanyl citrate (R33799: Janssen Pharmaceutica, Beerse, Belgium; Study II). After semen collection, surgical anaesthesia was reversed in all males with an i.v. injection of 20-25 mg diprenorphine hydrochloride (Revivon: Reckitt \& Coleman). Semen was collected by rectal-probe electroejaculation using the techniques previously described (Howard et al., 1984). Ejaculates were evaluated immediately in the field for volume, sperm concentration, percentage of sperm motility and sperm status (forward progression) using procedures described earlier (Howard et al., 1984). Each sperm motility and status estimate was a mean value based on subjective evaluations of 2 technicians. An aliquant from each raw, unfrozen sample was fixed in $1 \%$ glutaraldehyde for later evaluation of the morphological features of acrosomes by phase-contrast microscopy at $\times 1560$ (Pursel, Johnson \& Rampacek, 1972a; Howard, Bush \& Wildt, 1986).

Cryopreservation of spermatozoa. A summary of the experimental treatments including all dilution, equilibration, freezing, thawing and assessment steps for Studies I and II is provided in Fig. 1. For both studies, freeze processing of semen was conducted in an open-air, support vehicle in the field. Subsequent sperm thawing and evaluation procedures were performed under standard laboratory conditions. Using a single standardized freezing protocol, Study I was designed to compare the cryoprotective abilities of 7 different diluents. Immediately after semen evaluation, aliquants $(1 \mathrm{ml})$ of each ejaculate were pipetted into 8 plastic vials $(5 \mathrm{ml}$, Nalgene: Sybron Corp., Rochester, NY) and diluted in a $1: 1(\mathrm{v} / \mathrm{v})$ semen to diluent ratio with 7 cryoprotective diluents (TEST, TRIS, HEPT, PDV-62, TRIL, BF5F, EQ) at ambient $\left(21^{\circ} \mathrm{C}\right)$ temperature. The eighth aliquant was undiluted and processed in the same way as the diluted aliquants to demonstrate the most harmful effects of freezing unprotected spermatozoa.

The constituents of the diluents $(\mathrm{g} / 100 \mathrm{ml})$ were as follows. TEST consisted of $20 \%$ egg yolk, $4.83 \%$ tes-n-Tris, $1.15 \%$ Tris, $0.4 \%$ glucose and $5 \%$ glycerol. TRIS consisted of $20 \%$ egg yolk, $2 \cdot 82 \%$ Tris, $1 \cdot 3 \%$ citric acid, $1 \cdot 4 \%$ glucose and $5 \%$ glycerol. HEPT consisted of $20 \%$ egg yolk, $5.54 \%$ Hepes, $1.09 \%$ Tris, $0.4 \%$ glucose and $5 \%$ glycerol. PDV-62 consisted of $20 \%$ egg yolk, $11 \%$ lactose and $4 \%$ glycerol. TRIL is commercially available (Triladyl: Minitub, Tiefenbach, West Germany) and published ingredients included $20 \%$ egg yolk and $6 \%$ glycerol. BF5F consisted of $20 \%$ egg yolk, $1.6 \%$ glucose, $1.6 \%$ fructose, $1.2 \%$ tes-n-Tris, $0 \cdot 2 \%$ Tris, $4 \%$ glycerol and $0.5 \%$ surfactant mixture of sodium and triethanolamine lauryl sulphate (STLS, Equex: Nova Chemical Sales, Inc., Scitaute, MA). EQ consisted of $20 \%$ egg yolk, $5 \%$ glycerol, $0.5 \%$ STLS surfactant mixture, $50 \mathrm{ml} 11 \%$ lactose and $25 \mathrm{ml}$ glucose-EDTA solution (Loomis, Amann, Squires \& Pickett, 1983). 
STUDY I

DILUTION/EQUILIBRATION

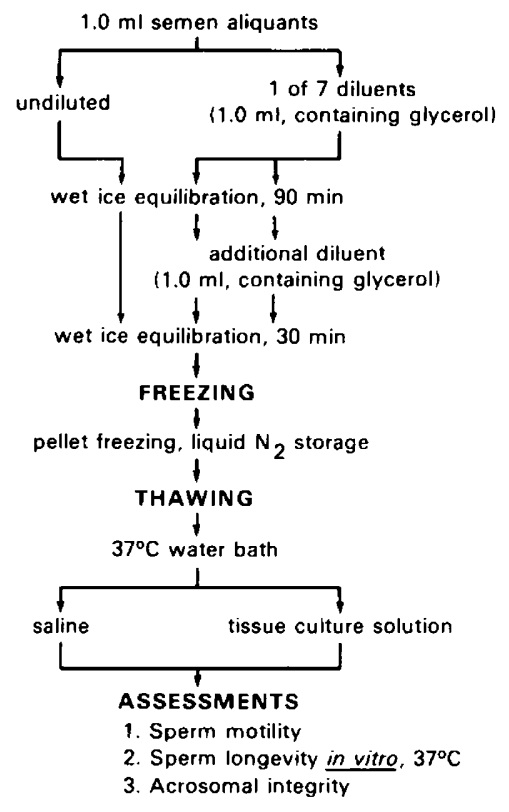

STUDY II

DILUTION/EQUILIBRATION



Fig. 1. Summary of Study I and II methods for diluting, equilibrating, freezing, thawing and evaluating elephant spermatozoa.

Diluents TEST, TRIS, HEPT and TRIL were developed for freeze-preserving bovine semen. Diluents PDV-62 and EQ were formulated for freezing carnivore (Platz, Wildt \& Seager, 1978) and equine (Loomis et al., 1983) semen, respectively. Diluent BF5F was a modification of diluent BF5 which was developed for freezing boar semen (Pursel \& Johnson, 1975). The undiluted ejaculate aliquant, the 7 diluted samples and an additional aliquant of each diluent were equilibrated concurrently on ice $\left(4^{\circ} \mathrm{C}\right)$ for $90 \mathrm{~min}$. After this interval, each of the semen-diluent combinations was extended further by adding $1.0 \mathrm{ml}$ of the appropriate diluent to make a final diluent:semen ratio of 2:1. Glycerolated diluents were used for the first and second dilution. Each extended mixture was equilibrated an additional $30 \mathrm{~min}$ on ice $\left(4^{\circ} \mathrm{C}\right.$ ) before being frozen by the pellet method (Nagase \& Niwa, 1964), which involved pipetting single drops $(30 \mu \mathrm{l})$ of cooled, diluted semen into $3 \times 4 \mathrm{~mm}$ indentations in a block of solid $\mathrm{CO}_{2}$. After a 3-min freezing interval, the solid $\mathrm{CO}_{2}$ block was inverted, depositing the frozen pellets into a liquid nitrogen bath. The pellets were spoon-transferred into labelled vials (Nalgene: Sybron Corp.) and stored in a liquid nitrogen container.

Study II was designed to evaluate further the optimal diluent from Study I (BF5F) and an eighth diluent SGI (Swine Genetics International, Inc., Cambridge, IA). The latter consisted of $18 \%$ egg yolk, $11 \%$ lactose, $6.6 \%$ glycerol and $1.5 \%$ STLS surfactant mixture. Both diluents were developed primarily for the cryopreservation of boar semen. Study II also examined the influence of equilibration interval and freezing procedure (pellet versus straw method). Each ejaculate was divided into four $1.0 \mathrm{ml}$ aliquants which were diluted $1: 1(\mathrm{v} / \mathrm{v})$ with BF5F or SGI (2 aliquants/ diluent). The first dilution was made with non-glycerolated diluent containing no surfactant. Immediately after dilution, aliquants were equilibrated at $5^{\circ} \mathrm{C}$ in a portable electronic cooler 
(Koolatron Caddy II: Koolatron Corp., Batavia, NY) for 60 or $120 \mathrm{~min}$. At the end of each of these intervals a second dilution $(1.0 \mathrm{ml})$ of the respective extenders containing glycerol and surfactant constituents was added and equilibration continued for $30 \mathrm{~min}\left(5^{\circ} \mathrm{C}\right)$. Therefore, 2 different equilibration intervals (60 and $30 \mathrm{~min}$ and 120 and $30 \mathrm{~min}$ ) were compared, and the end glycerol/ surfactant concentration for the BF5F and SGI diluent aliquants were $1 \cdot 3 / 0 \cdot 16 \%$ and $2 \cdot 2 / 0 \cdot 5 \%$, respectively. For freeze/storage, the extended, cooled semen was pelleted (as described in Study I) or manually pipetted into plastic $0.5 \mathrm{ml}$ straw containers. The latter were immediately placed horizontally in a rack positioned $5 \mathrm{~cm}$ above a liquid nitrogen bath $\left(-130^{\circ} \mathrm{C}\right)$. After $20 \mathrm{~min}$, all straws were plunged into liquid nitrogen and stored.

To determine the rate of temperature decline for each study, a thermocouple probe was placed in 2 vials of BF5F-diluted semen placed on ice $\left(4^{\circ} \mathrm{C}\right)$ (Study I) and in the electronic cooler (Study II). Temperature was recorded at $1.5-\mathrm{min}$ intervals for $150 \mathrm{~min}$. Cooling curves were plotted (Fig. 2) and time was calculated for the temperature of diluted semen to decline from $34^{\circ} \mathrm{C}$ (beginning of equilibration) to $5^{\circ} \mathrm{C}$. On ice, diluted semen reached $5^{\circ} \mathrm{C}$ in $4.5 \mathrm{~min}$ ('rapid cooling process'); in the electronic cooler, the $5^{\circ} \mathrm{C}$ temperature was achieved in $19.0 \mathrm{~min}$ ('slow cooling process').

Thawing and evaluation of spermatozoa. Physiological saline $(0.9 \%, \mathrm{w} / \mathrm{v})$ and a tissue culture solution (TCS, Tyrode: Difco Lab., Detroit, MI) were compared as thawing media for all pelleted semen aliquants. TCS is a balanced salt solution consisting of $1 \mathrm{~g}$ bacto-dextrose $/ 1,8 \mathrm{~g}$ sodium chloride $/ 1,0.2 \mathrm{~g}$ potassium chloride $/ 1,0.2 \mathrm{~g}$ calcium chloride $/ 1,0.1 \mathrm{~g}$ magnesium chloride $/ 1,0.05 \mathrm{~g}$ monosodium phosphate $/ 1,1 \mathrm{~g}$ sodium bicarbonate/ 1 in triple distilled water. Three pellets from. each aliquant were rapidly thawed in duplicate $12 \times 75 \mathrm{~mm}$ glass culture tubes containing $0.5 \mathrm{ml}$ saline or TCS warmed to $37^{\circ} \mathrm{C}$. Straws from Study II were thawed by placing in a $37^{\circ} \mathrm{C}$ water bath for $30 \mathrm{sec}$ before transferring semen to a glass culture tube. Each aliquant was examined immediately at $\times 400$ magnification ( 5 microscopic fields) for sperm $\%$ motility and progressive status $(0-5$ scale; 0 , no forward progression, 5, rapid forward progression; Howard et al., 1984). Serial examinations of these factors were made over time to determine the duration of sperm viability in vitro. In Study I, all thawed aliquants were maintained in a $37^{\circ} \mathrm{C}$ water bath. In Study II, 1 of each thawed, duplicate sample was maintained at $37^{\circ} \mathrm{C}$ and the other maintained at ambient $\left(21^{\circ} \mathrm{C}\right)$ temperature. After thawing (Study I), sperm motility and status ratings were made at 0, 15, 30, 45, 60, 90 and $120 \mathrm{~min}$ and continued hourly until no sperm motility was observed in at least 8 microscopic fields $(\times 400)$. In Study II, post-thaw sperm analysis was performed at 15 -min intervals until a $0 \%$ motility rating was observed.

Immediately after thawing, an aliquant $(50 \mu \mathrm{l})$ from each sample in Study I and from the straws and saline-thawed pellets in Study II was fixed in $1 \%$ glutaraldehyde. Acrosomal integrity was assessed blindly by examining 100 acrosomes/aliquant by phase-contrast microscopy $(\times 1560)$. Evaluations of acrosomes were based on criteria originally described by Pursel et al. (1972a) and categorized according to 2 morphological classes: normal acrosome (smooth, crescentic, acrosomal region) and abnormal acrosome (irregular, swollen, acrosomal region with loss of integrity).

Statistics. Values reported are means \pm s.e.m. The statistical significance of treatment effects was assessed by the analyses of variance (ANOVA) in a randomized complete block design by a computerized statistical program (Statistical Analysis System; SAS, 1982). Because of variation in ejaculate characteristics amongst individuals, each elephant was considered one complete replicate (block). A modified Duncan's multiple comparison procedure was used to test significant ANOVA results for selected pairwise comparisons (SAS, 1982). For statistical analyses of sperm viability in vitro, only the interval between thawing and the last observed $20 \%$ motility rating was used. This criterion was chosen on the practical basis that thawed ejaculates with a motility rating of $<20 \%$ would probably be inadequate for artificial insemination. Correlation coefficients were calculated between sperm concentration of the ejaculate and maximal post-thaw motility or longevity of motility. 


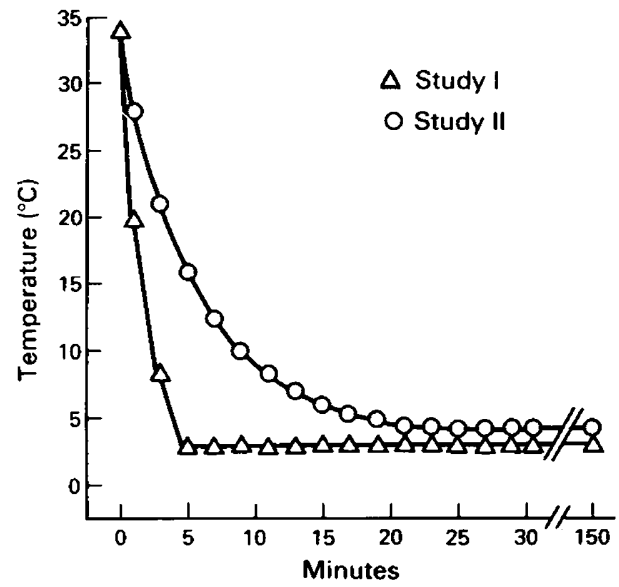

Fig. 2. Rate of temperature decline during equilibration of diluted semen on ice $\left(4^{\circ} \mathrm{C}\right)$ (Sturdy I) or in a portable electronic cooler (Study II).

Table 1. Ranking of cryoprotective diluents for elephant spermatozoa based on analysis of pellets thawed in (a) saline or (b) tissue culture solution (Study I) $(\mathrm{N}=6)$

\begin{tabular}{|c|c|c|c|c|c|c|c|}
\hline \multicolumn{2}{|c|}{$\begin{array}{l}\text { Sperm motility } \\
(\%)^{*}\end{array}$} & \multicolumn{2}{|c|}{ Sperm status } & \multicolumn{2}{|c|}{$\begin{array}{l}\text { Motility longevity } \\
(\min )^{*} \dagger\end{array}$} & \multicolumn{2}{|c|}{$\begin{array}{l}\text { Normal acrosomes } \\
(\%)^{*}\end{array}$} \\
\hline Rank & Mean \pm s.e.m. & Rank & Mean \pm s.e.m. & Rank & Mean \pm s.e.m. & Rank & Mean \pm s.e.m. \\
\hline \multicolumn{8}{|l|}{ (a) } \\
\hline BF5F & $53 \cdot 7 \pm 7 \cdot 5^{\mathrm{a}}$ & BF5F & $4 \cdot 2 \pm 0 \cdot 3$ & BF5F & $145 \cdot 2 \pm 31 \cdot 2^{a}$ & BF5F & $58 \cdot 9 \pm 2 \cdot 3^{a}$ \\
\hline HEPT & $39.8 \pm 6.8^{\mathrm{a}, \mathrm{b}}$ & PDV-62 & $4 \cdot 1 \pm 0.3$ & PDV-62 & $112 \cdot 8 \pm 28 \cdot 2^{\mathrm{a}, \mathrm{b}}$ & HEPT & $54 \cdot 8 \pm 2 \cdot 1^{\mathrm{a}, \mathrm{b}}$ \\
\hline PDV-62 & $37 \cdot 1+6 \cdot 8^{\mathrm{a}, \mathrm{b}}$ & TRIS & $3.9 \pm 0.3$ & HEPT & $99 \cdot 3 \pm 28 \cdot 2^{\mathrm{a}, \mathrm{b}}$ & EQ & $52 \cdot 9 \pm 2 \cdot 3^{b, c}$ \\
\hline TRIS & $33 \cdot 5 \pm 6 \cdot 8^{\mathrm{a}, \mathrm{b}}$ & EQ & $3.8 \pm 0.3$ & TRIS & $95 \cdot 6 \pm 28 \cdot 2^{\mathrm{a}, \mathrm{b}}$ & PDV-62 & $51 \cdot 8 \pm 2 \cdot 1^{\mathrm{b}, \mathrm{c}}$ \\
\hline TEST & $32.9 \pm 6.8^{\mathrm{a}, \mathrm{b}}$ & HEPT & $3.7 \pm 0.3$ & TRIL & $86 \cdot 3 \pm 28 \cdot 2^{\mathrm{a}, \mathrm{b}}$ & TEST & $50 \cdot 7 \pm 2 \cdot 1^{\mathrm{b}, \mathrm{c}}$ \\
\hline EQ & $31 \cdot 7+7 \cdot 5^{a, b}$ & TEST & $3.6 \pm 0.3$ & TEST & $86.0 \pm 28 \cdot 2^{\mathbf{a}, \mathbf{b}}$ & TRIL & $46 \cdot 3 \pm 2 \cdot 1^{\mathrm{c}, \mathrm{d}}$ \\
\hline TRIL & $27 \cdot 1 \pm 6 \cdot 8^{b}$ & TRIL & $3.5 \pm 0.3$ & EQ & $65 \cdot 3 \pm 31 \cdot 2^{b}$ & TRIS & $45 \cdot 0 \pm 2 \cdot 1^{\mathrm{c}, \mathrm{d}}$ \\
\hline \multicolumn{8}{|l|}{ (b) } \\
\hline BF $5 F$ & $60 \cdot 2 \pm 7 \cdot 5^{\mathrm{a}}$ & BF5F & $4 \cdot 3 \pm 0 \cdot 3$ & BF5F & $145 \cdot 9 \pm 31 \cdot 2^{\mathrm{a}}$ & BF5F & $56 \cdot 5 \pm 2 \cdot 3^{\mathrm{a}}$ \\
\hline HEPT & $44 \cdot 2 \pm 6 \cdot 8^{\mathrm{a}, \mathrm{b}}$ & TRIL & $4.0 \pm 0.3$ & HEPT & $108 \cdot 2 \pm 28 \cdot 2^{\mathrm{a}, \mathrm{b}}$ & HEPT & $54 \cdot 5 \pm 2 \cdot 1^{\mathrm{a}}$ \\
\hline TRIS & $41 \cdot 3 \pm 6 \cdot 8^{\mathrm{a}, \mathrm{b}}$ & HEPT & $3.8 \pm 0.3$ & TRIS & $106 \cdot 8 \pm 28 \cdot 2^{\mathrm{a}, \mathrm{b}}$ & EQ & $53 \cdot 3 \pm 2 \cdot 3^{\mathrm{a}}$ \\
\hline PDV-62 & $37 \cdot 7 \pm 6 \cdot 8^{\mathrm{a} . \mathrm{b}}$ & TRIS & $3.7 \pm 0.3$ & TRIL & $105 \cdot 3 \pm 28 \cdot 2^{\mathrm{a}, \mathrm{b}}$ & PDV-62 & $52 \cdot 8 \pm 2 \cdot 1^{\mathrm{a}, \mathrm{b}}$ \\
\hline TRIL & $34 \cdot 3 \pm 6 \cdot 8^{6}$ & PDV-62 & $3.6 \pm 0.3$ & PDV-62 & $91 \cdot 4 \pm 28 \cdot 2^{a, b}$ & TEST & $51 \cdot 7 \pm 2 \cdot 1^{\mathrm{a}, \mathrm{b}, \mathrm{c}}$ \\
\hline EQ & $32.7 \pm 7.5^{\mathrm{b}}$ & TEST & $3.5 \pm 0.3$ & TEST & $83 \cdot 5 \pm 28 \cdot 2^{\mathrm{a}, \mathrm{b}}$ & TRIL & $48 \cdot 5+2 \cdot 1^{b, c, d}$ \\
\hline TEST & $32 \cdot 1 \pm 6 \cdot 8^{b}$ & $\mathrm{EQ}$ & $3 \cdot 4 \pm 0.3$ & EQ & $43 \cdot 5 \pm 31 \cdot 2^{b}$ & TRIS & $47 \cdot 3 \pm 2 \cdot 1^{\mathrm{c}, \mathrm{d}}$ \\
\hline
\end{tabular}

* Column values with different superscripts differ $(P<0.05)$.

† Interval for thawed aliquant maintained at $37^{\circ} \mathrm{C}$ to reach a $20 \%$ motility rating.

\section{Results}

\section{Study $I$}

Mean \pm s.e.m. characteristics for ejaculates collected in 1982 were: ejaculate volume, $104 \cdot 5 \pm$ $65.3 \mathrm{ml}$; sperm motility, $72.5 \pm 5 \cdot 3 \%$; sperm progressive status, $3.8 \pm 0 \cdot 2$; sperm concentration, $2185 \cdot 0 \pm 681 \cdot 4 \times 10^{6}$ spermatozoa $/ \mathrm{ml}$. 


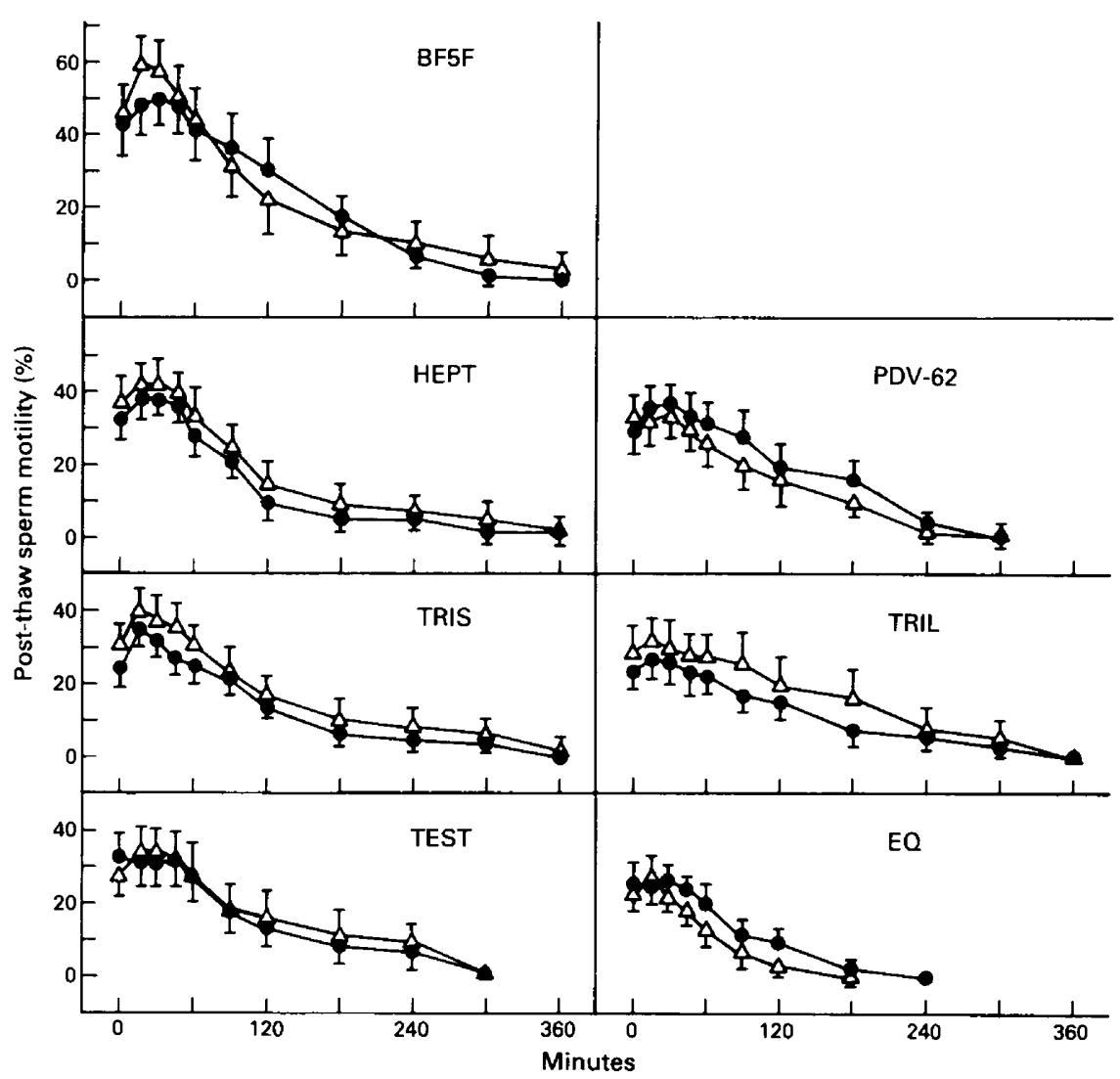

Fig. 3. In-vitro $\left(37^{\circ} \mathrm{C}\right)$ sperm motility profiles after pellet freezing using each of 7 cryoprotective diluents (Study I). Semen was thawed in saline (-) or tissue culture solution $(\triangle-\triangle)$. Values are means \pm s.e.m.

The spermatozoa subjected to the 'rapid freezing process' of Study I demonstrated post-thaw motility which was greatly influenced $(P<0.001)$ by the cryoprotective diluent used (Table 1$)$. When all diluents were compared, the medium used for thawing pellets also affected $(P<0.05)$ post-thaw sperm motility; however, the results between saline and TCS within each diluent were similar $(P>0.05)$. Neither diluent nor thawing medium influenced post-thaw sperm status $(P>0.05)$. After thawing, mean \% sperm motility and status ratings ranged from $27 \cdot 1$ to 60.2 and 3.4 to $4 \cdot 3$, respectively. Sperm concentration and post-thaw motility were not correlated $(r=0.01$, $P>0.05$ ). Significant differences were detected amongst elephants in post-thaw seminal traits $(P<0.01)$. Although similar percentages of sperm motility were observed amongst all ejaculates before cryopreservation, a wide variation in post-thaw motility occurred for certain males. Urine contamination of the semen was not evident based on ejaculate discoloration or increased acidity as indicated by routine $\mathrm{pH}$ evaluations of each sample.

When compared to the other 6 diluents, BF5F provided the greatest post-thaw motility and status ratings, regardless of thawing medium used (Table 1). The ranking of the remaining diluents varied based on thawing medium. Overall, motility-status values declined gradually over time in sigmoidal fashion regardless of the diluent or thawing medium used (Fig. 3); however, an initial increase in sperm motility was usually observed within the first $30 \mathrm{~min}$ after thawing. 

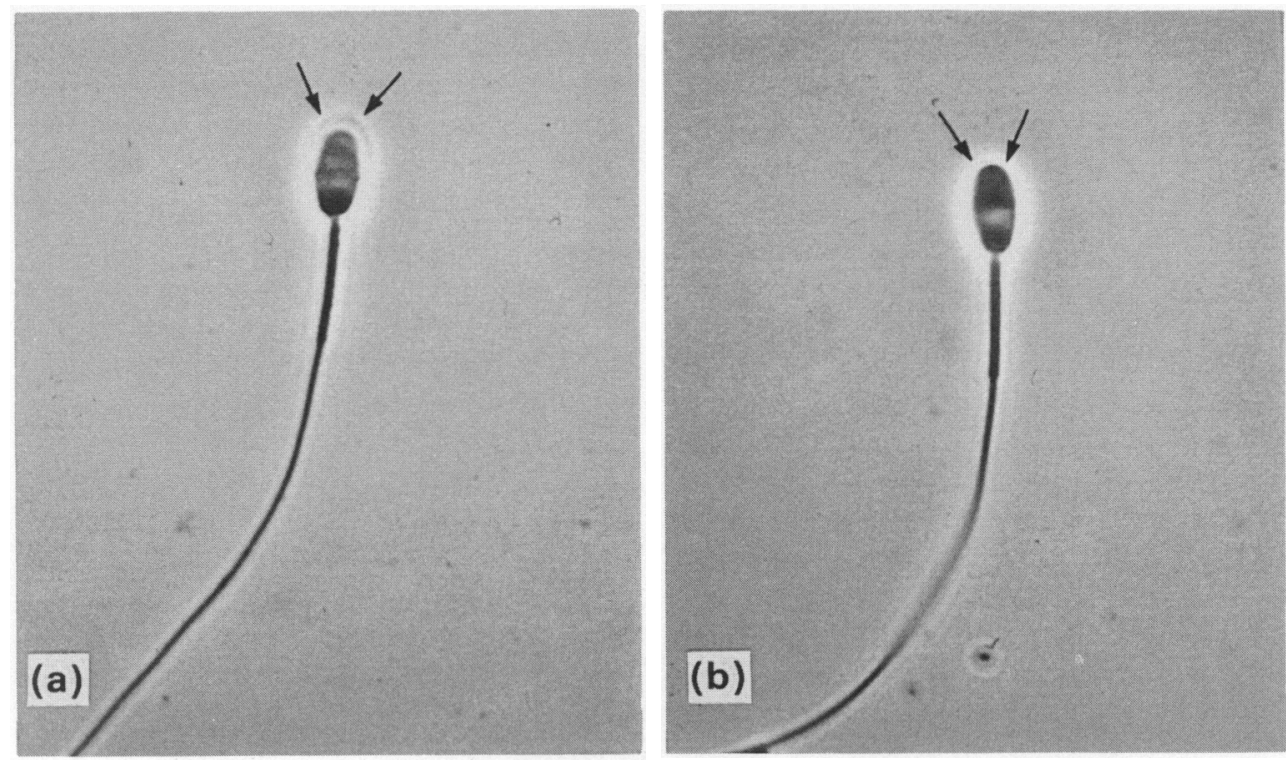

Fig. 4. Phase-contrast micrographs $(\times 1560)$ of African elephant spermatozoon with (a) an abnormal acrosome (arrows), consisting of an irregular, swollen acrosomal region, and (b) a normal, smooth, crescentic acrosomal region (arrows).

Table 2. Post-thaw motility ratings and acrosomal evaluations of elephant spermatozoa based on cryoprotective diluents and freezing-thawing method used (Study II) $(\mathrm{N}=7)$

\begin{tabular}{|c|c|c|c|c|c|}
\hline \multirow[b]{2}{*}{ Diluent } & \multicolumn{2}{|c|}{ Method } & \multicolumn{3}{|c|}{ Sperm } \\
\hline & Freeze & Thaw & Motility (\%) & Status & $\begin{array}{c}\text { Normal } \\
\text { acrosomes }(\%)\end{array}$ \\
\hline BF $5 F$ & $\begin{array}{l}\text { Pellet } \\
\text { Pellet } \\
\text { Straw }\end{array}$ & $\begin{array}{l}\text { Saline } \\
\text { TCS } \\
-\end{array}$ & $\begin{array}{l}41 \cdot 8 \pm 1 \cdot 9^{\mathrm{a}} \\
48 \cdot 6 \pm 1 \cdot 9^{\mathrm{b}} \\
13 \cdot 4 \pm 2 \cdot 1^{\mathrm{c}}\end{array}$ & $\begin{array}{l}3 \cdot 2 \pm 0 \cdot 1^{\mathrm{a}} \\
3 \cdot 8 \pm 0 \cdot 1^{\mathrm{b}} \\
2 \cdot 0 \pm 0 \cdot 1^{\mathrm{c}}\end{array}$ & $\begin{array}{l}11 \cdot 7 \pm 1 \cdot 4^{\mathrm{a}} \\
\overline{15 \cdot 9} \pm 1 \cdot 5^{\mathrm{a}, \mathrm{b}}\end{array}$ \\
\hline SGI & $\begin{array}{l}\text { Pellet } \\
\text { Pellet } \\
\text { Straw }\end{array}$ & $\begin{array}{l}\text { Saline } \\
\text { TCS } \\
-\end{array}$ & $\begin{array}{l}45 \cdot 5 \pm 1 \cdot 9^{\mathrm{a}, \mathrm{b}} \\
46 \cdot 6 \pm 1 \cdot 9^{\mathrm{a}, \mathrm{b}} \\
20 \cdot 4 \pm 2 \cdot 1^{\mathrm{d}}\end{array}$ & $\begin{array}{l}3 \cdot 6 \pm 0 \cdot 1^{\mathrm{b}} \\
3 \cdot 8 \pm 0 \cdot 1^{\mathrm{b}} \\
2 \cdot 3 \pm 0 \cdot 1^{\mathrm{c}}\end{array}$ & $\begin{array}{l}\frac{17 \cdot 1}{}-1 \cdot 4^{b} \\
21 \cdot 6 \pm 1 \cdot 5^{c}\end{array}$ \\
\hline
\end{tabular}

Values are mean \pm s.e.m.

Column values with different superscripts differ $(P<0.05)$.

The duration of post-thaw sperm motility in vitro was also influenced $(P<0.01)$ by the semen diluent used (Table 1). Sperm motility at $37^{\circ} \mathrm{C}$ was maintained for the longest interval ( $\sim 45 \mathrm{~min}$ ) in BF5F. With the exception of the PDV-62 diluent, the longevity ranking of the remaining diluents was unaffected by thawing medium.

Microscopic assessments of elephant spermatozoa revealed general conformational similarities to those of domestic ungulates; however, differences in acrosomal structure were apparent. Virtually no apical ridge was evident, even at $\times 1560$ magnification with phase-contrast or differential interference microscopy. Spermatozoa with irregular, swollen, acrosomal caps could be readily identified and, therefore, were used as the criterion for comparing an abnormal acrosome (Fig. 4a) to a normal counterpart containing a smooth acrosomal region (Fig. 4b). Each cryoprotectant 




Fig. 5. Duration of sperm motility in vitro in relation to cryoprotective diluent (BF5F or SGI), freezing method (pellets or straws) and maintenance temperature $\left(21^{\circ} \mathrm{C}\right.$ or $\left.37^{\circ} \mathrm{C}\right)$ (Study II). Values are means \pm s.e.m. and are calculated on the basis of evaluations initiated immediately after thawing until a $20 \%$ motility rating was observed. Panel I, pellets thawed in saline; II, pellets thawed in tissue-culture solution; III, straw results. Values with different superscript letters are significantly different, $P<0 \cdot 05$.

reduced acrosomal damage when compared with the frozen, undiluted raw aliquant $(40 \cdot 2 \pm 9 \cdot 3 \%)$, although the \% of spermatozoa with normal acrosomes was less in diluted-frozen semen (mean range, $45 \cdot 0-58 \cdot 9 \%$, Table 1) compared to unfrozen raw semen $(65 \cdot 7 \pm 7 \cdot 0 \%)$. Amongst all diluents, BF5F provided the greatest proportion of normal acrosomes after thawing $(58.9 \%$, saline; $56.5 \%$ TCS $)$. Thawing medium had no effect $(P>0.05)$ on acrosomal integrity within diluents.

\section{Study $I I$}

Mean \pm s.e.m. ejaculate characteristics in Study II males were similar $(P>0.05)$ to those obtained in Study I: ejaculate volume, $76.4 \pm 23 \cdot 2 \mathrm{ml}$; sperm motility, $66.4 \pm 5 \cdot 3 \%$; sperm progressive status, $3.9 \pm 0 \cdot 2$; concentration, $2381.9 \pm 697.4 \times 10^{6}$ spermatozoa $/ \mathrm{ml}$. An average of $55 \cdot 6 \pm 5 \cdot 1 \%$ ejaculated spermatozoa had acrosomes of normal appearance.

Overall, results were affected $(P<0.05)$ by diluent type, freezing method, thawing medium and maintenance temperature in vitro, but not by the 90 -min versus 150 -min cooling-equilibration intervals. When compared to results from Study I, the latter factor markedly affected the \% normal acrosomes observed after pellet-freezing. Normal acrosomal integrity was observed in only $8 \%$ of raw, undiluted spermatozoa subjected to the 'slow cooling process' before freezing.

Recovery of post-thaw sperm motility and progressive status after freezing varied amongst individual elephants $(P<0 \cdot 05)$. Other significant treatment effects are illustrated in Table 2 and Fig. 5. 


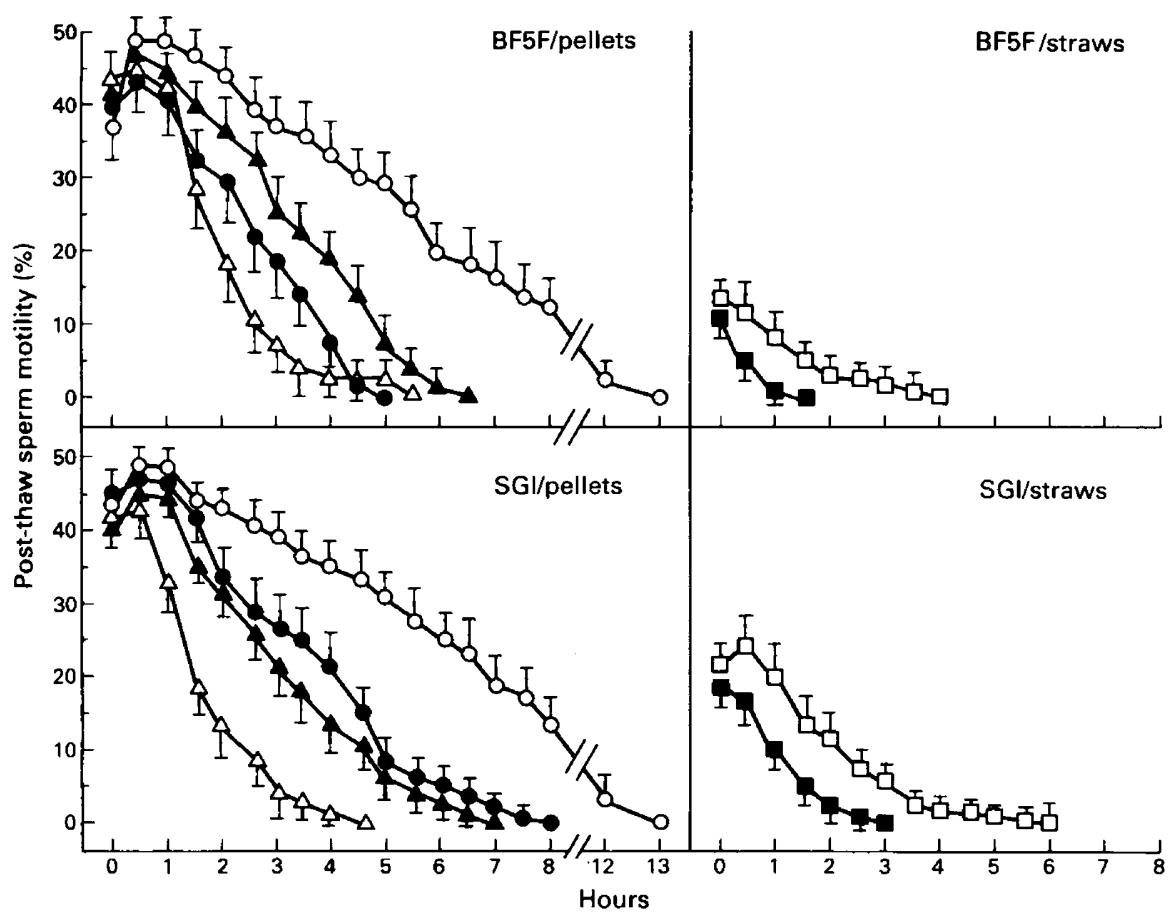

Fig. 6. In-vitro sperm motility profiles in relation to cryoprotective diluent (BF5F or SGI), freezing method (pellets or straws), thaw medium (saline or tissue culture solution) and maintenance temperature $\left(21^{\circ} \mathrm{C}\right.$ or $\left.37^{\circ} \mathrm{C}\right)$. Pelleted semen: saline, $21^{\circ} \mathrm{C}(\mathrm{O}-\mathrm{O})$, saline, $37^{\circ} \mathrm{C}$ $\left(\bullet-\mathrm{TCS}, 21^{\circ} \mathrm{C}(\Delta-\Delta) ; \operatorname{TCS} 37^{\circ} \mathrm{C}(\triangle-\triangle)\right.$. Semen in straws: $21^{\circ} \mathrm{C}(\square-\square) ; 37^{\circ} \mathrm{C}$ $(\mathbf{0}-\mathbf{0})$.

Based on post-thaw motility and status values, diluents BF5F and SGI were comparable cryoprotectants when the pelleting method and TCS thawing medium were used. Although saline gave similar motility ratings to TCS with the SGI extended semen, saline was not as effective $(P<0.05)$ as TCS with BF5F extended semen. Method of semen freezing had a significant $(P<0.001)$ influence on sperm motility and status, the pellet method providing thaw results superior to those with the straw method.

Duration of post-thaw motility in vitro was highly dependent $(P<0.001)$ on maintenance temperature, duration being greater at $21^{\circ} \mathrm{C}$ compared to $37^{\circ} \mathrm{C}$ (Figs $5 \&$ 6). Additionally, pelleted semen in either diluent maintained motility for much longer $(P<0.001)$ intervals than did semen stored in straw containers (Figs $5 \& 6$ ). Compared to other treatment groups, pelleted semen diluted in SGI, thawed in saline and maintained at $21^{\circ} \mathrm{C}$ demonstrated the longest sperm motility in vitro (range, $120-810 \mathrm{~min}$ ). Comparing the 2 diluents at each maintenance temperature, motility longevity was similar for pellets thawed in TCS and was severely shortened in straw-frozen samples. Maximal sperm motility ratings frequently were not achieved until 15-30 min after thawing; a similar observation was made from motility curve profiles of spermatozoa stored in straws (Fig. 6).

Overall, acrosomal damage in thawed, diluted samples (Table 2) was less severe than that observed in undiluted semen aliquants subjected to freezing. However, in all subgroups, the mean proportion of spermatozoa with intact acrosomes did not exceed $21.6 \%$. The SGI diluent was superior $(P<0.05)$ to $\mathrm{BF5F}$ in reducing acrosomal damage in pelleted spermatozoa. Although 
spermatozoa stored in straws had poor motility and longevity in vitro, a greater proportion $(P<0.05)$ of normal acrosomes was observed in SGI-diluted semen stored in straws than in frozen pellets (Table 2).

\section{Discussion}

The present results show that viable spermatozoa were recovered after cryopreserving elephant ejaculates. However, post-thaw survival (based on several evaluation criteria) was markedly influenced by the diluent, cooling equilibration process and freezing method used.

Elephant spermatozoa were similar to boar spermatozoa in response to cryopreservation. In Study I, the diluent BF5F was superior to other cryoprotectants. The BF5F diluent $(1.6 \%$ glucose and $1.6 \%$ fructose) is similar to BF5 extender ( $3.2 \%$ glucose) used successfully for freeze-storing boar semen (Pursel \& Johnson, 1975). With the second boar extender (SGI) in Study II, within thaw medium subgroups and when the pelleting method was used, there were no major differences between the BF5F and SGI diluents in sperm motility ratings. The only measurable advantage was that SGI-pelleted spermatozoa appeared less dependent on the type of thawing medium used. The freezability of elephant spermatozoa also resembled that of the boar with respect to the 2 freezing procedures tested. Although applied to storing domestic bull (Nagase \& Niwa, 1964; Lindstrom, Holmstrom \& Jokinen, 1972), ram (Graham, Crabo \& Pace, 1978) and dog (Platz \& Seager, 1977) spermatozoa, the pelleting technique has been used most extensively for pig semen (Pursel \& Johnson, 1975; Pursel, Schulman \& Johnson, 1978), partly because of poor post-thaw recovery rates of boar spermatozoa stored in conventional straw container systems (Schrader, Treu \& Hahn, 1977). Similarly, motility values of thawed elephant spermatozoa were markedly superior after pellet than after straw freezing.

Elephant ejaculates are frequently viscous (Howard et al., 1984) and this characteristic may be related to post-thaw recovery rates (Tischner, 1979). Although not objectively quantitated, semen viscosity varied markedly amongst individual males and it appeared that greater post-thaw motility recoveries and in-vitro longevities were achieved after freezing ejaculates with the least viscosity. The elephant's bulbourethral gland produces a highly viscous secretion whereas the seminal vesicles excrete a more watery fluid (Short, Mann \& Hay, 1967). Therefore, variation in seminal viscosity can probably be attributed to differences in accessory gland stimulation during electroejaculation. A critical component of pig semen diluents is the surfactant detergent, STLS, which decreases freeze-thaw damage in boar spermatozoa, probably by beneficially altering egg-yolk constituents (Graham, Rajamannan, Schmehl, Maki-Laurila \& Bower, 1971; Pursel et al., 1978). Whether STLS plays a role in altering cellular membrane integrity or reducing surface tension in viscous elephant semen remains to be determined. However, the beneficial effect of this ingredient appears highly dependent on other diluent components; diluent EQ with a similar surfactant concentration was least effective for freezing elephant spermatozoa.

Acrosomal integrity is a valuable criterion for determining cryoprotective properties of seminal diluents for both domestic (Pursel, Johnson \& Schulman, 1972b) and non-domestic (Howard, Pursel, Wildt \& Bush, 1981) species. The mature acrosome of the elephant appeared more similar to that of non-domestic equids (Howard et al., 1981), non-human primates (Leverage, Valerio, Schultz, Kingsbury \& Dorey, 1972), non-domestic felines (Wildt et al., 1983; Wildt, Howard, Hall \& Bush, 1986) and the dolphin (Fleming, Yanagimachi \& Yanagimachi, 1981) than to species such as cattle and pigs (Saacke \& Marshall, 1968; Pursel et al., 1972a). The immature spermatozoon of the elephant has an enlarged acrosome which is markedly condensed in the mature cell (Jones, Rowlands \& Skinner, 1974). This feature, which has been confirmed by electron microscopy (Heath et al., 1983), makes acrosomal assessment difficult using light microscopy.

Freezing the sperm cell can cause progressive deterioration of the acrosomal membrane or loosening of the acrosomal cap, the latter severely influencing fertilizing capacity (Pursel et al., 
1972b). The average numbers of freshly ejaculated spermatozoa with normal acrosomes were similar in Study I (66\%) and Study II (56\%). Marked differences were observed, however, in acrosomal damage after freezing of undiluted, raw semen aliquants (Study I, 40\%; Study II, 8\%), probably as a result of the cooling-equilibration rate. The more rapid cooling curve $\left(\sim 6.5^{\circ} \mathrm{C} / \mathrm{min}\right)$ and/or prolonged equilibration near $5^{\circ} \mathrm{C}$ in Study I appeared more beneficial than the slower freezing curve $\left(\sim 1.5^{\circ} \mathrm{C} / \mathrm{min}\right)$ of Study II for maintaining acrosomal integrity. Differences in acrosome damage also may have been related to glycerol exposure during equilibration. From the present studies, glycerol as a diluent component appears efficacious throughout the cooling-equilibration interval, perhaps in maintaining acrosomal integrity as observed in other species (Howard et al., 1981).

The observation of high post-thaw sperm motility and longevity rates in vitro, despite poor acrosomal integrity was an important finding in Study II. Previous reports have indicated that motility estimates are inadequate as a sole criterion for quality assessments of thawed monkey (Leverage et al., 1972), boar (Pursel et al., 1972b) and bull (Berndtson, Olar \& Pickett, 1981) semen. The acrosomal membrane of domestic ram spermatozoa is particularly sensitive to deterioration after cryopreservation, even though electron micrographs indicate little damage to the motor apparatus of the midpiece (Graham et al., 1978). Therefore, motility estimates alone are of limited value in evaluating post-thaw semen quality of elephants.

Critical to artificial breeding is the time that spermatozoa can be maintained in a viable condition before insemination. Raw, undiluted, elephant spermatozoa at $37^{\circ} \mathrm{C}$ maintain motility in vitro for $6 \mathrm{~h}$ or less (Howard et al., 1984). Although the present study demonstrated that longevity in vitro could be influenced by the cryoprotective diluent used, post-thaw maintenance temperature exerted a more profound effect. The duration of sperm motility was extended for up to $12 \mathrm{~h}$ by maintaining thawed ejaculates at 21 rather than $37^{\circ} \mathrm{C}$. This effect, which is probably mediated by a reduction in metabolic rate, warrants further investigation, including studies of durations of motility at temperatures as low as $4^{\circ} \mathrm{C}$.

We thank the National Parks Board of the Republic of South Africa and Dr U. de V. Pienaar for support and cooperation; the staff of Kruger National Park for their generous assistance and hospitality; Dr E. F. Graham of the University of Minnesota for providing the buffers for the diluents TEST, TRIS and HEPT; Minitub, West Germany, for providing the diluent Triladyl; L. L. Schulman for expertise in acrosomal evaluations; and S. F. Michie for assistance in manuscript preparation. This research was sponsored by the Friends of the National Zoo (FONZ), Washington, DC, and supported, in part, by a grant from the Charles Ulrich and Josephine Bay Foundation, administered by the American Association of Zoo Veterinarians. J.G.H. is partly supported by a Smithsonian Fellowship and both J.G.H. and M.C.S. are supported, in part, by a grant from the Women's Committee of the Smithsonian Associates, the Smithsonian Institution, Washington, DC.

\section{References}

Berndtson, W.E., Olar, T.T. \& Pickett, B.W. (1981) Correlation between post-thaw motility and acrosomal integrity of bovine sperm. J. Dairy Sci. 64, 346-349.

Fleming, A.D., Yanagimachi, R. \& Yanagimachi, H. (1981) Spermatozoa of the Atlantic bottlenosed dolphin, Tursiops truncatus. J. Reprod. Fert. 63, $509-514$.

Graham, E.F., Crabo, B.G. \& Pace, M.M. (1978) Current status of semen preservation in the ram, boar and stallion. XII Bien. Symp. Anim. Reprod. 47, 80-118.

Graham, E.F., Rajamannan, A.H.J., Schmehl, M.K.L., Maki-Laurila, M. \& Bower, R.E. (1971) Preliminary report on procedures and rationale for freezing boar semen. A.I. Digest 19, p. 12.

Heath, E., Jeyendran, R.S. \& Graham, E.F. (1983) Ultrastructure of spermatozoa of the Asiatic elephant. Zentbl. VetMed. C, Anat. Histol. Embryol. 12, 245-252.

Howard, J.G., Pursel, V.G., Wildt, D.E. \& Bush, M. (1981) Comparison of various extenders for freezepreservation of semen from selective captive wild ungulates. J. Am. Vet. Med. Assoc. 179, 1157-1161.

Howard, J.G., Bush, M., de Vos, V. \& Wildt, D.E. (1984) Electroejaculation, semen characteristics and serum 
testosterone concentrations of free-ranging African elephants (Loxodonta africana). J. Reprod. Fert. 72, 187-195.

Howard, J.G., Bush, M. \& Wildt, D.E. (1986) Semen collection, analysis and cryopreservation in nondomestic mammals. In Current Therapy of Theriogenology II pp. 1047-1053. Ed. D. Morrow. W. B. Saunders Co., Philadelphia.

Jones, R.C. (1973) Collection, motility and storage of spermatozoa from the African elephant, Loxodonta africana. Nature, Lond. 243, 38-39.

Jones, R.C., Rowlands, I.W. \& Skinner, J.D. (1974) Spermatozoa in the genital ducts of the African elephant, Loxodonta africana. J. Reprod. Fert. 41, $189-192$.

Jones, R.C., Bailey, D.W. \& Skinner, J.D. (1975) Studies on the collection and storage of semen from the African elephant, Loxodonta africana. Koedoe 18, $147-164$.

Leverage, W.E., Valerio, D.A., Schultz, A.P., Kingsbury, E. \& Dorey, C. (1972) Comparative study on the freeze preservation of spermatozoa: primate, bovine and human. Lab. Anim. Sci. 22, 882-889.

Lindstrom, U., Holmstrom, B.G. \& Jokinen, L. (1972) Pellets: Experiences and results of storage over 3 years. Proc. 7th Int. Cong. Anim. Reprod. \& A.I., Munich 2, p. 1427.

Loomis, P.R., Amann, R.P., Squires, E.L. \& Pickett, B.W. (1983) Fertility of unfrozen and frozen stallion spermatozoa extended in EDTA-lactose-egg yolk and packaged in straws. J. Anim. Sci. 56, 687-693.

Nagase, H. \& Niwa, T. (1964) Deep freezing bull semen in concentrated pellet form. Proc. 5th Int. Congr. Anim. Reprod. \& A.I., The Hague 4, p. 410.

Platz, C.C. \& Seager, S.W.J. (1977) Successful preg. nancies with concentrated frozen canine semen. $L a b$. Anim. Sci. 27, 1013-1016.

Platz, C.C., Wildt, D.E. \& Seager, S.W.J. (1978) Pregnancy in the domestic cat after artificial insemination with previously frozen spermatozoa. J. Reprod. Fert. 52, 279-282.

Pursel, V.G. \& Johnson, L.A. (1975) Freezing of boar spermatozoa: Fertilizing capacity with concentrated semen and a new thawing procedure. J. Anim. Sci.40, 99-102.

Pursel, V.G., Johnson, L.A. \& Rampacek, G.B. (1972a) Acrosome morphology of boar spermatozoa incubated before cold shock. J. Anim. Sci. 34, 279-283.

Pursel, V.G., Johnson, L.A., Schulman, L.L. (1972b) Loss of boar sperm fertilizing capacity associated with altered acrosome morphology during in vitro storage. Proc. 7th Int. Cong. Anim. Reprod. \& A.I., Munich 2, pp. 1595-1600.

Pursel, V.G., Schulman, L.L. \& Johnson, L.A. (1978) Effect of Orvus ES Paste on acrosome morphology, motility and fertilizing capacity of frozen-thawed boar sperm. J. Anim. Sci. 47, 198-202.

Ruedi, V.D. \& Kupfer, U. (1981) Semen collection in the African elephant (Loxodonta africana): a step towards artificial insemination. Proc. Am. Assoc. Zoo Vet., pp. 142-143.

Saacke, R.G. \& Marshall, C.E. (1968) Observations on the acrosomal cap of fixed and unfixed bovine spermatozoa. J. Reprod. Fert. 16, 511-514.

SAS. (1982) SAS User's Guide. Statistical Analysis System Institute, Inc., Cary, N.C.

Schrader, V.R., Treu, H. \& Hahn, R. (1977) Zur tiefgefrierkonservierung von ebersamen in kunststoffrohen. Dtsch. Tierarztl. Wschr. 84, 9-12.

Short, R.V., Mann, T. \& Hay, M.F. (1967) Male reproductive organs of the African elephant, Loxodonta africana. J. Reprod. Fert. 13, 517-536.

Tischner, M. (1979) Evaluation of deep-frozen semen in stallions. J. Reprod. Fert., Suppl. 27, 53-59.

Wildt, D.E., Bush, M., Howard, J.G., O'Brien, S.J., Meltzer, D., van Dyk, A., Ebedes, H. \& Brand, D.J. (1983) Unique seminal quality in the South African cheetah and a comparative evaluation in the domestic cat. Biol. Reprod. 29, 1019-1025.

Wildt, D.E., Howard, J.G., Hall, L.L. \& Bush, M. (1986) The reproductive physiology of the clouded leopard. I. Electroejaculates contain high proportions of pleiomorphic spermatozoa throughout the year. Biol. Reprod. (in press).

Received 19 February 1986 